\title{
The field and landscape of affordances: Koffka's two environments revisited
}

\author{
Julian Kiverstein ${ }^{1,5}$ (D) Ludger van Dijk ${ }^{2}$ (D) Erik Rietveld ${ }^{1,3,4,5}$
}

Received: 14 June 2018 / Accepted: 31 January 2019 / Published online: 20 March 2019

(c) The Author(s) 2019

\begin{abstract}
The smooth integration of the natural sciences with everyday lived experience is an important ambition of radical embodied cognitive science. In this paper we start from Koffka's recommendation in his Principles of Gestalt Psychology that to realize this ambition psychology should be a "science of molar behaviour". Molar behavior refers to the purposeful behaviour of the whole organism directed at an environment that is meaningfully structured for the animal. Koffka made a sharp distinction between the "behavioural environment" and the "geographical environment". We show how this distinction picks out the difference between the environment as perceived by an individual organism, and the shared publicly available environment. The ecological psychologist James Gibson was later critical of Koffka for inserting a private phenomenal reality in between animals and the shared environment. Gibson tried to make do
\end{abstract}

Our thanks to Jelle Bruineberg, Tony Chemero, Gary Hatfield, Adam Linson, Dave Ward, Alistair Isaac, Hayden Kee, Matt Sims, Uljana Feest, Tom Roberts and the audience at The World in Us: Gestalt Structure, Phenomenology and Cognitive Science conference held at the University of Edinburgh in July 2018. The work on this paper was supported by a European Research Council Starting Grant awarded to Erik Rietveld (ERC StG 679190, Affords-Higher). Ludger Van Dijk is supported by the Research Foundation Flanders Project Thinking in Practice: a Unified Ecological-Enactive Account (FWO postdoctoral fellowship $12 \mathrm{~V} 2318 \mathrm{~N}$ ).

$\bowtie$ Julian Kiverstein

j.d.kiverstein@amc.uva.nl

1 Academic Medical Centre, University of Amsterdam, Amsterdam, The Netherlands

2 Centre for Philosophical Psychology, Department of Philosophy, University of Antwerp, Antwerp, Belgium

3 Department of Philosophy, University of Twente, Enschede, The Netherlands

4 Institute of Logic, Language and Computation, University of Amsterdam, Amsterdam, The Netherlands

5 Amsterdam Brain and Cognition, Amsterdam, The Netherlands 
with just the concept of affordances in his explanation of molar behaviour. We argue however that psychology as a science of molar behaviour will need to make appeal both to the concepts of shared publicly available affordances, and of the multiplicity of relevant affordances that invite an individual to act. A version of Koffka's distinction between the two environments remains alive today in a distinction we have made between the field and landscape of affordances. Having distinguished the two environments, we go on to provide an account of how the two environments are related. Koffka suggested that the behavioural environment forms out of the causal interaction of the individual with a pre-existing, ready-made geographical environment. We argue that such an account of the relation between the two environments fails to do justice to the complex entanglement of the social with the material aspects of the geographical environment. To better account for this sociomaterial reality of the geographical environment, we propose a process-perspective on our distinction between the landscape and field of affordances. While the two environments can be conceptually distinguished, we argue they should also be viewed as standing in a relation of reciprocal and mutual dependence.

Keywords Koffka - Behavioural and geographical environment · Molar behaviour . Affordances · Solicitations · Ecological psychology · Field of relevant affordances · Landscape of affordances $\cdot$ Radical embodied cognitive science

\section{Introduction}

Kurt Koffka began his Principles of Gestalt Psychology by explaining what he saw as distinctive about the science of psychology as compared with other sciences. His answer is that psychology takes as its domain of inquiry "the place where the three great provinces of the world intersect, the provinces which we call inanimate nature, life and mind." (Koffka 1935: p. 10) Psychological explanations in his words "integrate" the sciences of the natural world, of life, and the mind. Koffka's vision of psychology as aiming to integrate the natural, life and human sciences amounts to a rejection of any dualist view that would separate the human mind from the natural world. He did not accept the arguments of the Verstehen philosophers writing at the time that questions concerning meaning, value and culture are the exclusive remit of the human sciences, and cannot be answered using the methods of natural sciences. However, he was equally critical of positivist conceptions of natural science as ultimately aiming for microphysical and mechanical explanations of natural phenomena. Koffka was critical of such a conception of the natural and life sciences for their failure to do justice to the reality of life and the mind (1935, p. 10). Koffka suggests it is a virtue of his Gestalt approach to psychology that it can avoid the shortcomings of such a positivist conception of science by integrating matter, life and mind through the notion of Gestalten.

Koffka used the term "Gestalten" to refer to natural processes conceived of as structured ordered wholes or unities. Any description of a physical system in terms of for instance mechanical forces would also have to explain how due to macroscopic relationships among physical variables the physical system exhibits structure and 
order as a whole. Koffka provides the compelling example of how a structure like a soap bubble remains in a relatively stable state of equilibrium with its surroundings (1935: p. 14). He describes how it is the spherical form of the bubble that explains how the microscopic elements that make up the bubble are temporarily and transiently held together over time. According to Koffka, psychology could be an integrative science because it could explain meaningfully structured and organized experiences of the world in terms of the macroscopically organized states of physical systems. Psychology as an integrative science could draw upon the quantitative explanation of the physical and life sciences because these explanations make appeal to Gestalten that can account for our everyday experience of perceiving and acting in a meaningful world.

Koffka's view of psychology as smoothly integrating everyday lived experience with the findings of the natural and life sciences is one he shares with a group of philosophers and scientists working today on the naturalization of phenomenology (Petitot et al. 1999; Gallagher 2005, 2013; Thompson 2007). In agreement with Koffka these philosophers take the experience of a meaningful world to be among the explananda for a science of the human mind. Cognitive science since its inception in the 1950s has drawn a hard distinction between experience as it is lived through by persons, and cognition conceived of as a sub-personal, mechanical process. They have focused on the latter and sought to explain cognition in terms of computational and mechanical operations carried out on sub-personal representational states. In doing so they have separated cognition from a person's everyday lived experience of the world. But such a separation is indefensible: cognitive processes are always intentionally directed towards the world as it is experienced by us (Koffka 1935; Köhler 1947, ch. 1; c.f. Varela et al. 1991: p. 52; Dewey 1929, ch. 1). The separation of cognition from everyday experience is premised on an untenable dualism of just the sort Koffka argued his Gestalt psychology could supersede.

In what follows we take up Koffka's recommendation that psychology should be a "science of molar behaviour" (Koffka 1935: p. 41). ${ }^{1}$ Molar behavior refers to the purposeful behaviour of the whole organism directed at objects and events that are meaningfully structured for the animal. It is molar behaviour that is investigated in radical embodied approaches to cognitive science (Chemero 2009; Bruineberg and Rietveld 2014). In targeting molar behaviour in its explanations, radical embodied cognitive science aims to do justice to the lived experience of engaging with a meaningful world just as Koffka did. Radical embodied cognitive science has intellectual roots that (via both Merleau-Ponty and Gibson amongst others) can be traced back to Koffka. It also inherits problems and questions that Koffka struggled to answer, as we try to bring out in what follows.

Section 2 begins by reconstructing Koffka's account of molar behaviour. We show how he was led to make a distinction between the "behavioural environment" and

\footnotetext{
1 Koffka contrasts molar structure with molecular structure in physical and biological systems. Molar structures exhibit organized and ordered behaviour: the behavior of each of the elements is dependent on the other elements that make up the structure. The soap bubble is an example of a molar structure. He tells us that molecular structures are by contrast made up of elements whose behaviour unfolds relatively independently and in isolation from the other elements that make up the structure. Koffka gives as an example the description of the nervous system in the behaviourist psychology of his day. Whether there are any systems whose structure is molecular in this sense is open to debate, as Koffka also recognised.
} 
what he called the "geographical environment", a term he used to refer to the publicly available shared environment. In Sect. 3 we turn to the ecological psychologist James Gibson's critique of Koffka's distinction. Gibson was deeply influenced by Koffka (a colleague of his at Smith College in the 1930s) while at the same time also being critical of mistakes and missteps he saw in Koffka's writings (see Gibson 1971; Heft 2001, ch. 6). Gibson took Koffka's behavioural environment to be a private phenomenal reality illicitly inserted in between an organism and its environment. He sought to avoid any such commitment by providing an account of the geographical environment (or what he referred to as the "ecological niche") as making available affordances. Gibson introduced his notion of affordances in part to do the work of Koffka's behavioural environment in explaining molar behaviour. However, we show how a science of molar behavior needs to distinguish affordances from their inviting character or valence. In our earlier work we have provided an account of why in a particular situation an animal selectively responds to some affordances but not others, based in part on the animal's needs and interests (see e.g. Bruineberg and Rietveld 2014; Rietveld et al. 2018; Rietveld 2008). This led us to distinguish the field of relevant affordances, from what we have called the landscape of affordances. We show how this distinction maps onto Koffka's two environments.

Having shown the importance of distinguishing these two notions of the environment in explaining molar behavior, in the final two sections of our paper we take up the question of how the two environments are related. Koffka argued the behavioural environment causally depends on two conditions - the physiology of the organism on the one hand, in interaction with the geographical environment on the other. Our distinction between the field and landscape of affordances can also be understood in causal terms. On this causal understanding it is an individual organism in causal interaction with a shared landscape of affordances which gives rise to a field of affordances. In Sect. 5 we argue that this causal account of how the two environments are related is not the whole story as it does not do full justice to the entanglement of the material with the social in the geographical environment. Doing so requires us to develop an account of the two environments in terms of the process in which both take form. The field and the landscape of affordances, we will argue, stand in a relation of reciprocal and mutual dependence with each other.

\section{Koffka's account of molar behaviour}

In chapter 2 of the Principles Koffka contrasts "molar behaviour" with what he describes as "molecular behaviour". Molar behaviour is the purposive, organized actions of the whole animal regulated by the perception of a meaningful environment. Examples Koffka gives include students and lecturers exchanging ideas in the classroom, "the pilot's navigation, the excitement of the spectators at a football game, Mr Babbit's flirtation, Galileo's work which revolutionized science, the hunting of the hound and the running of the hare" (1935, p. 25). He uses the term "molecular behaviour" to refer to the muscle contractions, and the mechanical reactions of nerve cells and fibres that take place within an organism in response to atomistic sensory stimulation. Koffka argued that explanations of molar behaviour would need to make 
reference to what he called the "behavioural environment". Behaviour he argued is not a bundle of reflex responses connected only by association to atomic sensory stimulation. Among the defining themes of Gestalt psychology is the rejection of what they called "the constancy hypothesis"- the claim that the contents of perception can be mapped point-by-point onto sensory stimulation. Koffka introduces the notion of the behavioural environment in rejecting what amounts to an equivalent hypothesis for behaviour. The muscle contractions that set the body in motion do not occur as isolated and independent events, but instead are interrelated, and combine to form holistically organized structures. $^{2}$

Koffka distinguishes the behavioural environment from what he refers to as the "geographical environment". The geographical environment is initially described by Koffka as the cause of sensory stimulation, or what he sometimes refers to as the "stimulus situation" (e.g. 1935, p. 29). ${ }^{3}$ The behavioural environment is introduced by Koffka "as a mediating link between geographical environment and behaviour, between stimulus and response" (p. 32). Koffka defends his distinction between the two environments by giving examples that show either that the same stimulus can give rise to multiple qualitatively different perceptual experiences, or that different stimuli can give rise to the same behaviour. He asks us to consider for example two chimpanzees that respond very differently to a wooden box placed in their cage. ${ }^{4}$ One chimpanzee uses the box to reach a bunch of bananas hanging from the roof of the cage just out of its reach. The other sits on the box despondent because it cannot work out how to reach the bananas. The difference in behaviour isn't explained by the box as a stimulus, which is the same for the two chimpanzees. The chimpanzees differ in the relation they can establish with the box. What they each see is something of pragmatic significance, but in the one case but not the other this provides them with problem-solving insight (Koffka 1935: p. 31).

Koffka is clear that for him the behavioural environment is only a place-holder for an explanation. Ultimately, the behaviour of an organism must admit of integration with explanations of processes within the organism conceived of as a "physico-chemical system" (p. 48). To think otherwise would be to accept an ontological distinction between animal behaviour and the behaviour of the rest of the physical world. This would stand in conflict with the Gestalt vision of psychology as an integrative science of nature, life and mind. Koffka subscribed to what Epstein and Hatfield (1994) have

\footnotetext{
2 Nowadays similar claims are made by some philosophers in the context of distinguishing mechanistic from dynamical explanation. Chemero and Silberstein (2008) for example argue that mechanistic explanations are committed to strong localization and decomposition. This is the assumption that behaviour can be explained by appeal to mechanisms which can be functionally decomposed into components each of which performs its own functional operations and that when organized in the right way explain some behaviour of interest. Chemero and Silberstein argue that complex systems have non-linear causal properties that do not allow for localization of functions in well-defined parts. Such systems have constituents whose behaviour is highly coherent and correlated, and thus cannot be "treated even approximately as a collection of uncoupled individual parts" (p. 16). This is a formulation that could have been taken straight from the writings of Koffka or Köhler in their critique of the then dominant behaviourist movement in psychology. For an interesting discussion of the relation of Gestalt ideas to systems theory see Stadler and Cruse (1994).

${ }^{3}$ We will see below however that the geographical environment is not exhausted by being the source of stimulus situation.

${ }^{4}$ The example alludes to the experiments Wolfgang Köhler performed with chimpanzees on the island of Tenerife in World War One (see Köhler 1917/1925).
} 
described as a "programmatic reductionism" (p. 166). He held that molar behaviour should ultimately admit of explanation in terms of physiological states and processes. But as we have been discussing, Koffka also argued for a distinction between the behavioural and geographical environments. His distinction between the two environments threatens to render the facts of psychology as a science of molar behaviour metaphysically discontinuous with the facts of physics and biology. At least such an outcome would be implied should it turn out that explanation of behavior in physics and biology is always of molecular behaviour.

Koffka was sensitive to the problem. His solution was to hypothesise that the physiological processes that take place on the side of the organism are molar, and not molecular. We will interpret the claim that physiology is molar as the view that the contribution of each element of the nervous system to behaviour depends upon its interactions with other elements. The relevant contrast is with molecular physiological processes: isolated and local sensations that map onto "locally stimulated excitations that run their course without regard to other excitations." (Koffka 1935: p. 97) Thus Koffka writes for instance:

...no local stimulation can determine the corresponding excitation by itself, as the constancy hypothesis implied, but only in connection with the totality of stimulation. The form of the process in extension must depend upon the whole extended mosaic of stimulation, and all its parts become what they are as a result of the organization of the extended process...the same change in local stimulation can produce different changes in the behavioural world according to the total organization which is produced by the total stimulation. (Koffka 1935: p. 97)

Koffka endorsed the following three claims:

(1) Explanation of molar behaviour in psychology must ultimately be given in physiological terms.

(2) The physiological processes invoked in psychological explanations are molar, not molecular in structure.

(3) Explanations of molar behaviour must make reference to the behavioural environment.

These three claims entail that the meaningful structure in the behavoural environment must be isomorphic with molar structured physiological processes on the side of the animal. Each Gestalt in the behavioural environment maps one-to-one onto a stable macroscopic physiological state the organism reaches from very different initial conditions. The organisation of the behavioural environment into Gestalten is thus due to a general tendency of physical systems to form stable patterns in response to sensory stimulation. Koffka famously asked "why do things look at they do?" (1935, ch. 3) His account of the behavioural environment suggests his answer to this question was that things look as they do because the physiological processes within the organism have a certain organization, which spontaneously takes form on the basis of proximal stimulation (see e.g. Koffka 1935: pp. 62-67).

There are however two distinct ways to think about this relation of isomorphism. On the first understanding, the isomorphism can be understood entirely from the side 


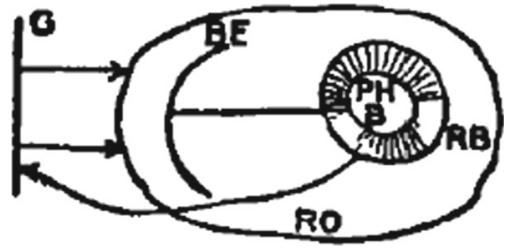

Fig. 1 Koffka's figure (from p. 40 of his 1935) illustrates the causal interaction of the geographical environment $(\mathrm{G})$; the behavioural environment $(\mathrm{BE})$, and the real organism $(\mathrm{RO})$. (PHB) refers to phenomenal behaviour or real behaviour as it appears to the agent of this behaviour as a response to the behavioural environment

of the organism. The processes internal to the organism's brain stand in a relation of isomorphism to Gestalten. We will call this the "methodological solipsist" reading of Gestalten. Gestalten on this interpretation of Koffka are "internal" to the individual organism in the sense that what the organism experiences in the behavioural environment can be identified without making reference to the geographical environment. The geographical environment provides sensory stimulation to the organism and is the place in which action has its effects. Otherwise it is screened-off from the organism by the behavioural environment.

Such an interpretation of Koffka garners some support from fig. 1 above reproduced from chapter 2 of his Principles. Figure 1 seems to be naturally interpreted as showing the behavioural environment as being internal to the organism. The geographical environment $(\mathrm{G})$ causally impinges on the real organism (RO) by providing sensory input that perturbs self-organising physiological processes internal to the boundary of the organism. These physiological processes settle into stable, global patterns of organization that map one-to-one onto the organism's experience of the meaningfully structured behavioural environment. The arrow from RB back to $\mathrm{G}$ indicates that RB in turn causes changes in the geographical environment. We can think of this in terms of the organism's behaviour in the geographical environment being initiated on the basis of its experience of the behavioural environment.

However on closer inspection such a reading of Koffka doesn't quite do justice to his account of isomorphism. ${ }^{5}$ Koffka tells us the behavioural environment depends upon two sets of conditions, "one inherent in the geographical environment, one in the organism" (1935, p. 31). The behavioural environment can thus better be thought of in relational terms as typically requiring the organism to stand in a relation to particular things, events or places belonging to the geographical environment. The relation of isomorphism holds between Gestalten and the organism in its dynamical coupling with its environment. We can find two lines of reasoning in support of such a reading of Koffka. First, he says the "behavioural environment depends upon the geographical" (Koffka 1935: p. 31). Consider again the example of the two chimpanzees and their different uses of the box. It is the box in the geographical environment the ape can use as a seat or as a stool. Second, it is the geographical environment that is changed by the animal's actions: "the fruit is eaten and thereby ceases to exist as a fruit." (Op cit.) The results of the individual's molar behaviours are changes to the shared geographical

\footnotetext{
5 We are grateful to an anonymous reviewer for pressing us to be more careful on this issue.
} 
environment. Gestalten on this relational interpretation have to be understood in terms of two sets of conditions-one internal to the organism, the other belonging to the geographical environment.

Given this relational reading of Gestalten, Koffka's distinction between the two environments can be understood in the following way. The geographical environment is the shared meaningfully structured world, while the behavioural environment is the geographical environment as it appears to an individual. One and the same thing, place or event belonging to the geographical environment can show up as offering very different behavioural opportunities to different perceiving animals. In Koffka's well-known tale, a rider traverses the frozen Lake of Constance on horseback, unaware of the hidden dangers. The lake as part of the geographical environment appears to him only as a solid snow-covered terrain. When he learns the snow-covered terrain was in fact the frozen but fragile surface of the lake he drops dead from the shock of the danger he has just unwittingly negotiated. The same aspect of the geographical environment appears differently to the rider at different times, first as a 'snow covered plane', and later as a 'fragile, life-threatening frozen lake'.

In the next section we show how Koffka's concept of the behavioural environment was to serve as the inspiration for James Gibson's concept of affordances. Gibson was however critical of Koffka for holding an unnecessarily subject-dependent or private, phenomenalistic view of the behavioural environment. Gibson seems to have read Koffka as defending what we have labelled the methodological solipsist reading of Gestalten. We will argue that once one adopts a relational reading of Gestalten, Koffka can naturally be read as anticipating Gibson's notion of affordances.

\section{The meaningful environment}

In his discussion of demand character Koffka describes how objects can be perceived as having value and meaning as a part of their physiognomic character (Koffka 1935, ch. 8). An object can wear its meaning and value on its face just as a person sometimes shows what they are feeling in their facial expression, and in their bodily demeanor. A letter box can for instance invite us to break off our conversation and cross the street when we have an important letter we need to post, but will leave us indifferent when we do not (1935, p. 345). A hunk of beefsteak can look delicious to a person that enjoys eating meat and has worked up an appetite (1935, Ibid), but morally disgust a vegan, and leave the carnivores amongst us that have already eaten feeling neither one way nor another. These considerations were an important influence on James J. Gibson. He coined the term "affordances" in order to capture the sense in which the environment external to animals is pragmatically significant. Gibson tells us that his "concept of affordance is derived from the concepts of valence, invitation, and demand character but with a crucial difference. The affordance of something doesn't change as the need of the observer changes." (Gibson 1979: pp. 138-139; Rietveld and Kiverstein 2014) Gibson distinguishes Lewin's notion of demand character and valence which depends upon a perceiver's needs and interests, from affordances which do not (Gibson 1979: p. 139). The letter box continues to afford access to the postal service even when you 
don't have any need to send a letter, the beefsteak affords eating even if you are vegan and will never eat meat.

We suggested above that the behavioural environment is the geographical environment as it appears to the individual perceiver. Gibson seems to have read Koffka as committed to a methodologically solipsist interpretation of Gestalten, and by extension of the behavioural environment. Such a reading of the behavioural environment, Gibson argued, could only generate unnecessary philosophical puzzles:

If this means that each animal and every man behaves in his own private world, as it can be taken to mean, it is surely mischievous. Koffka did not go so far, but he nevertheless persisted in believing that there are two distinct meanings of the basic notion of an organism-in-an-environment. (Gibson 1971: p. 7)

Thus, Gibson tried to collapse the distinction between the two environments. Gibson thought he no longer needed to make appeal to a behavioural environment; he could make do with just the notion of the ecological niche conceived of as a "set of affordances" (Gibson 1979: p. 128). The term "affordance" was coined by him to refer to the possibilities for action the shared environment makes available, independent of any particular individual and their needs and interests. Gibson wrote:

An affordance is neither a subjective nor an objective property; or it is both if you like. An affordance cuts across the dichotomy of subjective-objective and helps us to understand its inadequacy. It is equally a fact of the environment and a fact of behaviour. It is both physical and psychical, yet neither. An affordance points both ways, to the environment, and the observer. (Gibson 1979: p. 129)

We suggest what Gibson meant when he wrote that affordances are neither subjective nor objective is that affordances should be thought of as relational in nature (Chemero 2003; Stoffregen 2003; Rietveld and Kiverstein 2014). If X stands in a relation R to $\mathrm{Y}$ then $\mathrm{R}$ is not an intrinsic property of either $\mathrm{X}$ or $\mathrm{Y}$ taken in isolation but is a property of each because of how they are related. Affordances are neither properties of the environment taken independently from animals (i.e. "objective" properties). Nor are they properties of an animal's subjective experience the animal projects onto the environment (i.e. "subjective" properties). They are both subjective and objective because they are features, properties or events that exist only because of how animals and their environments are related.

Thus for Gibson, it was affordances and not the behavioural environment that mediates between the individual and the shared publicly available geographical environment. We note however that Koffka's behavioural environment need not be viewed as a private phenomenal reality through which the organism gains access to the rest of the world. It can instead be thought of as the shared publicly available geographical environment as it appears to an individual. The snow-covered plain just is the frozen Lake of Constance. It is the latter that appears to the rider, but it does so as a solid snow-covered plain, not as a life-threatening frozen lake. Koffka could therefore happily agree with Gibson that the environment that regulates an animal's behaviour is an ecological niche, a shared public environment of affordances. He could also agree with Gibson that affordances do not owe their existence to the changing needs of individuals. The post-box forms a part of the behavioural environment in part because 
of a particular individual's need to post a letter. But at the same time the post-box can only form a part of the behavioural environment of the individual because it is a part of a shared geographical environment. When Koffka talks about the geographical environment as the source of organized, molar structured sensory stimulation, perhaps he was not that far apart from Gibson after all. We can think of the affordances of the geographical environment as providing the "source of stimulation" (Gibson 1966, ch. 1), the external molar structure that maps one-to-one to the organism's Gestalten.

Nor is it clear to us that those that would follow Gibson can escape making something along the lines of Koffka's distinction between the two environments. Indeed, Gibson too noted that individuals might feel a "temporary special attraction" (Gibson 1979: p. 139) to affordances depending on their needs. A distinction is thus required between affordances which exist independently of any particular individual, and the invitation of an affordance that draws an individual into action (Withagen et al. 2012; Rietveld 2008). ${ }^{6}$ The central question for psychology as a science of molar behaviour is why in a particular situation an animal is moved to act by only some affordances, while other affordances do not move them in the least. Animals engage in activities that are contextually appropriate and well-adapted to their circumstances. What is it that accounts for the contextual sensitivity and appropriateness of their behaviour? Why is it for instance, that when we visit a restaurant we tend to eat only from our own plate, and not from the plates of the strangers sat at the table next to us? We typically refrain from eating the food from a stranger's plate, unless these people invite us to do so even while we may be tempted to do otherwise. We will suggest in the next section that distinguishing affordances from their inviting character really amounts to a reformulation of Koffka's distinction between two environments. Gibson's ecological approach to psychology inherits from Koffka a distinction between the two environments. But having distinguished the two environments how should we think about the relation between them? In the remainder of our paper we provide an answer to this question.

\section{The landscape and field of affordances}

Any explanation of molar behaviour must explain why it is that agents are selectively responsive, acting only on affordances that are relevant to them, while ignoring those that are irrelevant. The behavioural environment which Koffka saw as regulating molar behaviour can be thought of as made up of inviting affordances. The question of how certain of the available affordances stand out as inviting is thus equivalent to

\footnotetext{
6 In a forthcoming chapter Baggs and Chemero (2018) make a related distinction between the environment as the habitat of animals, and an animal-specific Umwelt, a notion that originates in Von Uexküll (1934). The habitat refers for them to the environment of an ideal or typical individual member of a species. The Umwelt as they use the term is the environment as it exists for a particular individual animal because of the skills it has developed over time and because of its needs and interests at any given moment in time. The distinction between the habitat and the Umwelt is thus related to but not the same as the distinction we've made between the landscape and field (as Baggs and Chemero note in their Table 1). While we agree Baggs and Chemero are right to mark this important conceptual distinction, we note that they do not directly address the question we engage with in the rest of our paper as to how to bring the two environments back together having distinguished them conceptually.
} 
the question of how the behavioural environment emerges out of the geographical environment. By answering these questions we will thereby cast light on how the two environments are related.

In our earlier work on skilled intentionality, we have made a distinction between the field of relevant affordances, and the landscape of affordances in which the field is situated (Bruineberg and Rietveld 2014; Rietveld et al. 2018). ${ }^{7}$ The landscape of affordances is our term for an animal's ecological niche understood as a set of affordances (Gibson 1979: p. 128). We've suggested that affordances should be understood in relation to the abilities available in a form of life, and not in relation to the abilities of an individual agent (Rietveld and Kiverstein 2014). ${ }^{8}$ We borrow the phrase "form of life" from Wittgenstein (1953), using the phrase as Wittgenstein did to refer to the relatively stable and regular patterns of activity found among individuals taking part in a practice or a custom. ${ }^{9}$ We propose to understand affordances in terms of the regularities in how a kind of animal lives. Here we are following a pointer in Gibson when he writes: "The possibilities of the environment and the way of life of the animal go together" (Gibson 1979: p. 143). The landscape of affordances has a physical and material structure, but it is not to be confused with reality as it is described in physics. The landscape of affordances is pragmatic in the sense that it is organized and structured at the spatial and temporal scale of the patterns of regular activity available in a form of life. It is the public environment an individual shares with the other members of the forms of life to which the individual belongs.

Like the landscape of affordances, the field of relevant affordances is also relational in nature, but it is relative to an individual. It is made up of affordances that vary over time in their soliciting power. Merleau-Ponty's (1942/1963) example of the football field may help to illustrate. The football field as a setting is a complex aspect of the landscape of affordances, but it is also a field of relevant affordances for the players taking part in the match. The field of the striker is "pervaded by lines of force" that draws them to make a pass to another player, or to go for a strike on goal (see MerleauPonty 1942/1963, p. 169). ${ }^{10}$ The trainer may see an opportunity to move between

\footnotetext{
7 In what follows we sometimes use the term "field" and "landscape" as shorthand for the "field of relevant affordances", and the "landscape of affordances" respectively.

8 To be more precise, we take affordances to be "relations between aspects of the sociomaterial environment in flux and abilities available in a form of life" (Van Dijk and Rietveld 2017, p. 8; Rietveld and Kiverstein 2014).

9 See for instance $\$ 23$ of the Investigations in which he uses the term in relation to the many activities people perform in speaking a language. In a note entitled "Cause and effect: Intuitive Awareness" Wittgenstein writes:
}

I want to say: it is characteristic of our language that the foundations on which it grows consists in steady (firm) forms of life [Lebensformen], regular ways of acting. (Klagge and Nordman 1993: p. 397)

He uses the term Lebensformen in the plural here to refer to regular ways of living as we do above. These regularities can be found at multiple spatial and temporal scales. They can be found in groups of humans such as academics as distinguished from politicians but also in humans in general as distinguished from say birds, or in mammals as distinguished from mollusks.

10 Koffka provides a strikingly similar description of this example in discussing the research of a sport's psychologist of his day Hartgenbusch. Koffka tells us how the football player sees the pitch as "a field of changing lines whose principle direction leads towards the goal” (p. 44, quoting Hartgenbusch 1927: p. 50). 
defenders that the striker fails to appreciate, and shout from the sideline promoting the relevant action possibility for the striker. The opportunity is not (or at least not yet) a part of the striker's field of relevant affordances, but it does belong to the wider landscape of affordances. It is the availability of the affordance in the landscape here and now that makes it possible for the trainer to attempt to promote it to the striker.

The relevant affordances that make up an individual's field invite action. They have demand character. An animal's interests and needs make it the case that some of the available affordances in the landscape but not others have demand character. The relevance of an affordance thus varies with the needs and interests of the individual while the affordance as an aspect of the sociomaterial environment remains relatively enduring and constant. At the same time an affordance's inviting character (its "relevance" or "soliciting power") plays a role in drawing the individual agent into action. One does indeed "feel a special attraction" to a letter box when one has an urgent letter to post (Gibson 1979: p. 139). The inviting character of relevant affordances in the field is thus to be distinguished from the affordances belonging to the landscape, which continue to remain available to others when this individual is no longer present.

The field of relevant affordances may be interpreted as an environment as it shows up for the individual subject (Koffka's behavioural environment). The landscape of affordances can be thought of as the publicly shared world common to different members of a form of life (Koffka's geographical environment). How are the field of relevant affordances relative to the individual, and the landscape of affordances relative to the shared form of life related? One way to think about their relation would be in terms of a two-way causal interaction of the individual with the wider landscape of affordances. The individual is changed by and is simultaneously changing the landscape of affordance through their actions. Koffka seems to have conceived of the relation between the two environments in this way. He says for instance that it is the geographical environment that is changed by acting. The "fruit is eaten and thereby ceases to exist as a fruit; the snow bridge is broken and gives place to a hole; the box is actually transported when the ape uses his "stool" (Koffka 1935: p. 31).

In earlier work we have described how the field forms out of this two-way causal interaction of the individual with the landscape. The phenomenology of being drawn into action by inviting affordances we've characterized as a tendency towards an optimal grip (Bruineberg and Rietveld 2014). ${ }^{11}$ The individual experiences her grip on the inviting affordances as deviating from an optimum. She is then moved to act in such a way as to improve her grip on the affordances she cares about in some way. We talk of grip as tending towards optimality because the organism prefers a state of relative equilibrium with the environment, and is acting to correct for disequilibrium. This bodily stance is something the organism must actively maintain in relation to a dynamic field of multiple relevant affordances, hence our describing it in terms of grip.

\footnotetext{
11 We borrow this notion from Merleau-Ponty (1962/2002) and his description of perception of the world as one of maximum prise. The word "optimal" might be somewhat misleading here. We speak therefore of a tendency towards optimal grip in order to capture the sense in which optimal grip in a dynamically changing set of circumstances (and by an individual with limited abilities) is something that will always elude the agent.
} 
On this view of the relation between the two environments, landscape (geographical environment) and field (behavioural environment) stand in a relation of reciprocal causal dependence. The field emerges out of the landscape on the basis of the interaction of the individual with the landscape of affordances. In the next section we show how such an account is not the whole story. While useful and productive for a science of molar behaviour, it doesn't fully do justice to the entanglement of the social and material in the landscape of affordances. Although we agree it makes sense to distinguish the two environments conceptually we argue against their ontological separation by showing how field and landscape co-constitute each other in process across time-scales.

\section{The reciprocal dependence of the landscape and field: a process perspective}

Our main aim in the last section of our paper is to show how both landscape and field take shape in the activities of individuals as they enact affordances. We will argue that the two environments should be thought of as taking shape together in an ongoing process (c.f. Van Dijk and Rietveld 2018). ${ }^{12}$ In our process account of affordances, affordances are enacted by individuals and unfold over time. From this process perspective, the landscape and field can then be distinguished in their temporal relation to one another. Insofar as affordances have an already determined, material and shared character they belong to the landscape. Insofar as affordances have a future directed, open-ended and affective character they give shape to the field of particular individuals. By being responsive to inviting affordances, individuals, each in their own way, act in ways that contribute to maintaining and determining the availability of the landscape in the future.

Recall that on our view, the affordances the landscape makes available depend for their existence on the regular ways of doing things in a form of life. The availability of the affordances in the landscape is thus in part dependent on the history of a past activity by a plurality of individuals. The constellations of materials making up the landscape takes form across this history of practices. Think for example of the ways that the street named Broadway in New York has been shaped by people traveling by horse, by car, by bus and by builders laying bricks, making sidewalks on the sides of the road (rather than say in the middle of the road), placing the traffic lights (straight up, turned in the right direction and with their colors in the right place), etc. The material structure of the landscape is thus entangled in, and inseparable from the normatively regulated patterns of individuals' activity. Any material constellation is thus in fact 'sociomaterial' through and through (Orlikowski 2007).

The development of the possibilities the landscape makes available unfolded over a long history, and are continuing to actively take shape as practices unfold. Although persistent and forming over much larger time scales than the activity of an individual, the landscape therefore does not possess ready-made structure. The landscape makes

\footnotetext{
$\overline{12}$ The arguments of this section build on a recently published article. See Van Dijk and Rietveld (2018) for details.
} 
available certain possibilities in the here and now because of the previously established ways of doing things (cars can ride where horses used to pull carriages). Materiality is historical. We can think of the affordances as they pertain to the landscape as forming the history in terms of which the environment for an individual is now available. That is, the landscape asserts itself in the (socio)material constraints on current behavior (just like on Broadway the freedom of movement of cars is constrained by the traffic lights and buildings that have been erected along the road and its sidewalks).

When we deny that the landscape comes with a ready-made structure we in no way mean to undercut the shared material reality of the landscape. On the contrary, the landscape constrains the activities available to its participants due to its materiality. Consider the case of the postbox discussed by Koffka. The postbox can act as the container of small objects in part due to its material form. The material structure of the landscape of affordances poses very real constraints on what individuals can do. It does so we have suggested in part because of the shared and practical history that has led to the landscape forming this particular constellation of materials. While the materiality of the landscape constrains activity, it does not dictate or cause it - it is always open to other ways of going on. Cars can drive on sidewalks (e.g. to avoid obstacles) and even traffic lights can be removed if necessary for an important transportation job. Postboxes can partake in a multitude of activities that do not involve the sending of letters. One might for instance use the postbox as a landmark when giving someone directions into town. One can lean against the postbox casually while waiting for a bus. Perhaps others see you and begin to follow your example. But when an individual has a letter to send to a long standing friend and responds to the invitation of the postbox to post their letter, they are continuing and contributing to the sustaining of a specific pattern of activity - the slowly dying art of letter writing.

The landscape of affordances because of its long history provides the terms in which an individual can engage with it. It foregrounds the determination of possibilities that have been achieved up to that point through the past history of individual's acting. It is up to the situated and skilled individual to continue and determine the possibilities the landscape provides further in acting. By being determined up to a certain point, constraining but not causing action, affordances remain open to being taken up in new ways. They can invite skilled and caring organisms to continue them in a novel and innovative way. Part of what we experience in being invited to act by a relevant affordance is the unfinished, future-directed character of affordances. In experiencing one's surrounds as an inviting field, one experiences the need for further determining of the possibility for action in one's current activity.

We are thus proposing a view of the individual's engagement with the landscape as an unfolding temporally extended process. The landscape makes available possibilities not because it has some pre-given form and structure but through the development of particular form and structure, through a past history of engagement. When the individual is invited to act by relevant affordances (and actually acts on that invitation) this is simultaneously a further determining of the possibilities the landscape makes available. What this process view of affordances points to, is therefore the temporal and reciprocal relation between landscape and field. On short time scales, the field depends on the landscape, which constrains the possibilities currently available. Over longer time scales the landscape depends on the field because it is through the invi- 
tation of relevant affordances that practices are maintained, and kept alive. The field is then always "at the forefront" of the evolving landscape, continuing it in a particular way, sometimes in new and hitherto unexplored directions (Van Dijk and Rietveld 2018, p. 14). Think of musicians that play jazz: the affordances of musical instruments to make jazz music depends upon musicians that know the history of jazz, and can maintain this history whilst also building on it through their own improvisations. Thus when an individual acts, the field of relevant affordances and the landscape of affordances are jointly enacted, albeit at different time scales and to different degrees. The practical constellations of materiality the landscape makes available are maintained and continued together by individuals invited to act in ways that are constrained by the landscape.

The landscape of affordances "sets up the conditions of its own continuation" by inviting individuals, with their own particular history to act in and on it (Van Dijk and Rietveld 2018, p. 21 ff.). Responding to invitations typically will sustain existing patterns of practice, but every now and then an invitation might be so unorthodox that it can better be understood as setting up a new pattern of activity. Each organism grows up in a multitude of practices and contributes to the maintenance of a landscape of affordances through having their development sculpted by other members of these practices. However, each growing and learning individual takes their own unique and particular path to do so- a path that is shaped by and shapes the skills, sensitivities and current concerns of that individual. Thus, in any concrete situation the field of relevant affordances forms at the focal point (or rather the line) where both the individual's path and the landscape intermingle and together develop further. As they make their way together, neither remains unchanged (cf. Ingold 2011, 2018).

The field of relevant affordances and the landscape of affordances are jointly enacted when individuals act, albeit at different time scales and to different degrees. The material structure of the landscape takes form over time through a history of normatively regulated patterns of acting. Through this past history of engagement the landscape forms the terms in which the environment now invites the individual to act. The molar and meaningful structure of the landscape doesn't causally determine the actions of individuals. Individuals are invited to act on the basis of their developmental history. In doing so, they contribute to maintaining and continuing, and further determining the possibilities the landscape offers going into the future.

\section{Conclusion}

In times of increasing specialization and compartmentalization in the sciences, connecting the natural sciences, the life sciences and everyday lived experience is an important aspiration of radical embodied cognitive science. Koffka and Gibson made progress with such integration by seeking to make it scientifically intelligible how perception of a meaningful environment is possible. They developed a research programme in psychology that provided explanations of our everyday experience of perceiving and acting in a meaningful environment, coherent and consistent with explanation in the physical and biological sciences. In this paper we've been concerned with Koffka's claim that psychology should be a science of molar behaviour. 
The environment we perceive is as Koffka noted an environment of significant possibilities for action, or what Gibson came to refer to as "affordances". It is a meaningful environment because of the affordances it offers. Psychology if it is to explain our perception of a meaningful environment must explain our selective engagement with affordances. It must be as Koffka argued a science of molar behaviour.

The notion of affordances was introduced by Gibson as part of an explanation of behaviour that starts from the mutuality of agent and environment. Recognising the complementarity of animals and their environments is, we suggest, essential to answering the gestalt psychologist's question of how perception of a meaningful environment is possible. Constructing psychological explanations that start from the animal in its environment will however mean building bridges between psychology, biology and physics in just the way the gestalt psychologists sought to do. It will mean pitching psychological explanation at the right spatial and temporal scale relative to the bodily capacities of animals (Gibson 1979). It will require investigating behaviour as a selforganising process that unfolds through the reciprocal coupling of the agent and its environment (Chemero 2009; Bruineberg and Rietveld 2014).

We've shown how Gibson's distinction between demand character and affordances, developed in response to Koffka, potentially implies a distinction between the field of relevant affordances as it exists in relation to the individual and the landscape of affordances shared by a form of life. We've shown how to think of the relation between the field and landscape as one of reciprocal dependence. Affordances are in flux and unfold in the landscape through the ongoing patterns of activity of individuals responding to the invitation of relevant affordances. Through these patterns of activity affordances set up the conditions for their own continuation. Molar behaviour should be thought of as fundamentally anticipatory-individuals are responsive to the direction of the process which they help to sustain, and keep alive through their activities. The revolution in psychology that the Gestaltists began has thus led to a truly integrative view of human behaviour in which through their activities human agents come to be enmeshed with their sociomaterial surroundings.

Funding JK and ER are supported by the European Research Council (ERC) Starting Grant 679190 (awarded to Erik Rietveld). Ludger van Dijk is supported by the Research Foundation Flanders (FWO, project Thinking in practice: a unified ecological-enactive account [12V2318N]).

Open Access This article is distributed under the terms of the Creative Commons Attribution 4.0 International License (http://creativecommons.org/licenses/by/4.0/), which permits unrestricted use, distribution, and reproduction in any medium, provided you give appropriate credit to the original author(s) and the source, provide a link to the Creative Commons license, and indicate if changes were made.

\section{References}

Baggs, E. \& Chemero, A. (2018). The third sense of environment. In J. Wagman \& J. Blau (Ed's) Perception as information detection: Reflections on Gibson's ecological approach to visual perception. London: Taylor \& Francis.

Bruineberg, J., \& Rietveld, E. (2014). Self-organisation, free energy minimisation and optimal grip on a field of affordances. Frontiers in Human Neuroscience, 8, 599. https://doi.org/10.3389/fnhum.2014. 00599.

Chemero, A. (2003). An outline of a theory of affordances. Ecological Psychology, 15(2), 181-195. 
Chemero, A. (2009). Radical embodied cognitive science. Cambridge, MA: MIT Press.

Chemero, A., \& Silberstein, M. (2008). After the philosophy of mind: Replacing scholasticism with science. Philosophy of Science, 75(1), 1-27.

Dewey, J. (1929). Experience and nature. The Paul Carus lectures. La Salle, IL: Open Court Publishing.

Dreyfus, H. L., \& Kelly, S. D. (2007). Heterophenomenology: Heavy-handed sleight-of-hand. Phenomenology and the Cognitive Sciences, 6(1-2), 45-55.

Epstein, W., \& Hatfield, G. (1994). Gestalt psychology and the philosophy of mind. Philosophical Psychology, 7(2), 163-181.

Gallagher, S. (2005). How the body shapes the mind. Oxford: Oxford University Press.

Gallagher, S. (2013). On the possibility of naturalizing phenomenology. In D. Zahavi (Ed.), Oxford handbook of contemporary phenomenology. Oxford: Oxford University Press.

Gibson, J. J. (1966). The senses considered as perceptual systems. Boston: Houghton-Mifflin.

Gibson, J. J. (1971). The legacies of Koffka's Principles. Journal of the History of the Behavioural Sciences, 7(1), 3-9.

Gibson, J. J. (1979). The ecological approach to visual perception. Hove, East Sussex: Psychology Press.

Hartgenbusch, H. G. (1927). Gestalt psychology in sport. Psyche, No. 27. Originally published as: Beobachtungen und Bemerkungen zur Psychologic des Sports. Psych. Forsch., 7, 386-397.

Heft, H. (2001). Ecological psychology in context: James Gibson, Roger Barker, and the legacy of William James's radical empiricism. Mahwah, NJ: Lawrence Erlbaum Associates.

Ingold, T. (2011). The perception of the environment: Essays on livelihood, dwelling and skill. London: Routledge.

Ingold, T. (2018). Anthropology and/as education. London: Routledge.

Klagge, J., \& Nordmann, A. (Eds.). (1993). Ludwig Wittgenstein: Philosophical occasions (1912-1951). London: Hackett Publishing Company.

Koffka, K. (1935). Principles of Gestalt psychology. New York: Harcourt Brace.

Köhler, W. (1917/1925). The mentality of apes. New York: Harcourt Brace.

Köhler, W. (1947). Gestalt psychology: An introduction to new concepts in modern psychology. New York, NY: Liverlight Publishing Company.

Lewin, K. (1926). Vorbemerkungen über die psychischen Kräfte und Energien und die Struktur der Seele. Psych. Forsch., 7, 294-329.

Merleau-Ponty, M. (1942/1963). The structure of behaviour. (Alden L. Fisher, Trans.). Boston, MA: Beacon Press.

Merleau-Ponty, M. (1962/2002). The phenomenology of perception (C. Smith, Trans.). London: Routledge.

Orlikowski, W. J. (2007). Sociomaterial practices: Exploring technology at work. Originazation Studies, 28(9), 1435-1448.

Petitot, J., Varela, F. J., Pachoud, B., \& Roy, J.-M. (Eds.). (1999). Naturalizing phenomenology: Issues in contemporary phenomenology and cognitive science. Stanford: Stanford University Press.

Rietveld, E. (2008). Situated normativity: The normative aspect of embodied cognition in unreflective action. Mind, 117, 973-1001. https://doi.org/10.1093/mind/fzn050.

Rietveld, E., Denys, D., \& Van Westen, M. (2018). Ecological-enactive cognition as engaging with a field of relevant affordances: The skilled intentionality framework (SIF). In A. Newen, L. De Bruin, \& S. Gallagher (Eds.), The Oxford handbook of $4 E$ (embodied, embedded, extended, enactive) cognition. Oxford: Oxford University Press.

Rietveld, E., \& Kiverstein, J. (2014). A rich landscape of affordances. Ecological Psychology, 26(4), 325-352. https://doi.org/10.1080/10407413.2014.958035.

Stadler, M. A., \& Cruse, P. (1994). Gestalt theory and synergetics: From psychophysical isomorphism to holistic emergentism. Philosophical Psychology, 7(2), 211-226.

Stoffregen, T. A. (2003). Affordances as properties of the animal-environment system. Ecological Psychology, 15(2), 115-134.

Thompson, E. (2007). Mind in life: Biology, phenomenology, and the sciences of mind. Cambridge, MA: Harvard University Press.

Van Dijk, L., \& Rietveld, E. (2017). Foregrounding sociomaterial practice in our understanding of affordances: The skilled intentionality framework. Frontiers in Psychology, 7, 1969. https://doi.org/10. 3389/fpsyg.2016.01969.

Van Dijk, L., \& Rietveld, E. (2018). Situated anticipation. Synthese. https://doi.org/10.1007/s11229-01802013-8.

Varela, F., Thompson, E., \& Rosch, E. (1991). The embodied mind. Cambridge, MA: MIT Press. 
Von Uexkull, J. (1934/1957) A stroll through the worlds of animals and men. In C. Schiller (Ed.) Instinctive behaviour. New York: International Universities Press

Withagen, R., De Poel, H. J., Araújo, D., \& Pepping, G. (2012). Affordances can invite behavior: Reconsidering the relationship between affordances and agency. New Ideas in Psychology, 30(2), 250-258.

Wittgenstein, L. (1953). Philosophical investigations (G. E. M. Anscombe, Trans.). Oxford: Blackwell Publishing.

Publisher's Note Springer Nature remains neutral with regard to jurisdictional claims in published maps and institutional affiliations. 